delivery, superimposed PE and/or FGR; $\mathrm{n}=14)$ the median gestation at delivery was 36.5 (26-38) vs 37.8 (37-39) weeks in the good outcome group $(\mathrm{n}=10)$. Customised birthweight centiles were significantly lower in the poor outcome group [10 (0-86) vs 67 (15-96); p < 0.05], BMI was not different between the groups. There was a trend towards a higher PWv in the poor outcome group at 16 weeks $9.29 \pm 1.66$ vs $8.21 \pm 1.06 \mathrm{~m} / \mathrm{s}$ $(\mathrm{p}=0.09)$. Peripheral $(101 \pm 10.6 \mathrm{vs} 97.9 \pm 8.6 \mathrm{mmHg})$ and central $(90.5 \pm 9.9$ vs $87.2 \pm 8.7 \mathrm{mmHg})$ mean arterial pressure were not different between the groups at the same gestation. There was no difference in the PWv between the groups at 22 weeks gestation.

Conclusion Measures of arterial stiffness in early pregnancy may be more informative than blood pressure measurements alone in the prediction of adverse pregnancy outcome in women with chronic hypertension.

\section{PM.42 HEPATITIS C ASSOCIATED THROMBOCYTOPENIA IN PREGNANCY: PREGNANCY MANAGEMENT AND MORBIDITY}

doi:10.1136/archdischild-2013-303966.124

${ }^{1} \mathrm{C}$ Monteith, 'S Cooley, ${ }^{2} \mathrm{~J}$ Lambert, ${ }^{2 B}$ Kelleher, 1,2F Ni Ainle, 'M Eogan. ${ }^{1}$ Rotunda Hospital, Dublin, Ireland; ${ }^{2}$ Mater Hospital, Dublin, Ireland

Hepatitis $\mathrm{C}$ virus (HCV) is associated with massive worldwide morbidity and mortality. Recent studies have implicated HCV in pathogenesis of immune thrombocytopenia. ${ }^{12}$ However, the impact in pregnancy has not been explored in detail.

We looked at the impact of HCV on maternal platelet count, bleeding and multidisciplinary management of labour and delivery in a retrospective series of HCV-infected pregnant women. Women with a detectable HCV viral load were identified between 2009 and 2011. Platelet count and HCV viral load were determined at booking, 32/40 and delivery in HCV-infected women and controls.

Thrombocytopenia was identified in $10.3 \%$ of $\mathrm{HCV}$-infected pregnant women in comparison to only $2.1 \%$ of age-matched controls $(p<0.01)$. Mean platelet count at delivery was significantly lower in HCV-infected women compared with controls $(p=0.01)$. There was no significant difference in estimated blood loss (EBL) at delivery. Regional anaesthesia was performed in $73 \%$ of thrombocytopenic HCV-infected women.

In the first study to date to investigate the impact of thrombocytopenia upon pregnancy management in HCV-infected women. We demonstrated a significantly higher frequency of thrombocytopenia and a significantly lower platelet count in HCV-infected pregnant women compared with controls. We recorded no significant fetal bleeding complications.

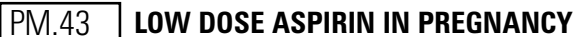

doi:10.1136/archdischild-2013-303966.125

DD Boban, E Ferguson, M Farquharson. Wishaw General Hospital, Glasgow, UK

Introduction Hypertensive disorders in pregnancy are associated with significant risks to both mother and baby. NICE recommends women at high risk of pre-eclampsia to be given $75 \mathrm{mgs}$ of Aspirin from 12 weeks gestation until delivery.

${ }^{1}$ Rajan, S.K., B.M. Espina, and H.A. Liebman, Hepatitis C virus-related thrombocytopenia: clinical and laboratory characteristics compared with chronic immune thrombocytopenic purpura. Br J Haematol, 2005. 129(6): p. 818-24.

${ }^{2}$ Zhang, W., et al, Role of molecular mimicry of hepatitis $\mathrm{C}$ virus protein with platelet GPIIIa in hepatitis C-related immunologic thrombocytopenia. Blood, 2009. 113(17): p. 4086-93.
Aim To review current practise on use of low dose aspirin in pregnancy for prevention of pre-eclampsia and to establish safety and benefit of its use.

Method Data were collected retrospectively for 295 patients who booked in for antenatal care between Jan 2010 and Jan 2011. The presence of risk factors for pre-eclampsia, use of low-dose aspirin, antenatal complications and delivery outcomes were recorded on a database and analysed. We investigated whether all eligible women were given aspirin and compared outcomes amongst those eligible who were given aspirin against those eligible who were not given aspirin.

Results $26 \%$ of all antenatal bookers were eligible for low dose aspirin of which only $18 \%$ were given aspirin. None of the patients who were eligible and prescribed aspirin developed preeclampsia as opposed to $7 \%$ in those who were eligible and did not receive aspirin. There was also a reduction in induction of labour (21\% and $38 \%$ ) with use of low dose aspirin, but no influence on gestation at delivery, mode of delivery, birth weight or admission to NNU.

Conclusions The use of low-dose aspirin is safe with no side effects in study group and beneficial in prevention of pre-eclampsia. Midwives have been issued with pocket guides to indications for aspirin to improve compliance.

\section{PM.44 PREGNANCY OUTCOMES IN BLACK WOMEN WITH CHRONIC HYPERTENSION IN THE UK}

doi:10.1136/archdischild-2013-303966.126

M Homsy, K Bramham, B Parnell, C Nelson-Piercy, LC Chappell. King's College London, London, UK

Introduction Women with chronic hypertension (CHT) have poor pregnancy outcomes. Black ethnicity is associated with both adverse pregnancy events, and CHT. Data regarding pregnancy outcome for black women in the UK are limited. Aims: 1) To assess pregnancy outcomes in women with CHT according to ethnicity; 2) To evaluate changes in pregnancy outcome over a decade

Methods Women with CHT who delivered at St. Thomas' Hospital between 2001-2011 were identified from a hospital database, and pregnancy outcomes extracted. Outcomes between black and white women were compared. Multiple pregnancies were excluded.

Results Black women had significantly worse neonatal outcomes than white women with CHT (Table). There were no significant differences in CHT pregnancy outcome between 2001-2011.

\section{Abstract PM.44 Table 1}

\begin{tabular}{|c|c|c|c|}
\hline Outcome & $\begin{array}{l}\text { Black } \\
(N=564)\end{array}$ & $\begin{array}{l}\text { White } \\
\text { ( } N=367)\end{array}$ & ${ }^{*}$ Adjusted OR \\
\hline Still birth & $11(2 \%)$ & $3(1 \%)$ & $2.41(0.67-8.71)$ \\
\hline $\begin{array}{l}\text { Gestation at delivery (w) } \\
\text { Median(IOR) }\end{array}$ & $38(33-40)$ & $39(38-40)^{* *}$ & - \\
\hline Delivery $<34$ weeks & $59(10.5 \%)$ & $12(3.2 \%)$ & 7.25 (2.67-19.74) \\
\hline Delivery $<37$ weeks & $129(22.9 \%)$ & $41(10.8 \%)$ & $2.91(1.68-5.03)$ \\
\hline $\begin{array}{l}\text { Birthweight }(\mathrm{g}) \\
\text { Median(IOR) }\end{array}$ & $\begin{array}{l}\text { AB3060 } \\
(2560-3500)\end{array}$ & $\begin{array}{l}\text { AB3300 } \\
(2920-3700)^{*}\end{array}$ & - \\
\hline $\begin{array}{l}\text { Small for Gestational Age } \\
<5^{\text {th }} \text { Centile }\end{array}$ & $72(12.8 \%)$ & $32(8.4 \%)$ & $2.04(1.11-3.75)$ \\
\hline $\begin{array}{l}\text { Small for Gestational Age } \\
<10^{\text {th }} \text { Centile }\end{array}$ & $109(19.3 \%)$ & $48(12.7 \%)$ & $1.81(1.11-3.00)$ \\
\hline $\begin{array}{l}\text { Neonatal intensive care } \\
\text { admission }\end{array}$ & $57(10.1 \%)$ & $19(5.97 \%$ & $2.79(1.29-5.73)$ \\
\hline
\end{tabular}

${ }^{*}$ Adjusted for BMI, maternal age, parity ${ }^{* *} \mathrm{P}<0.0001$

Conclusion Black ethnicity is associated with significantly worse pregnancy outcomes in women with CHT. There have been no 